NASATM-

AIAA 79-1820R

Full-Scale Wind-Tunnel Study of the Effect

of Nacelle Shape on Cooling Drag

V. R. Corsiglia, J. Katz, R. A. Kroeger

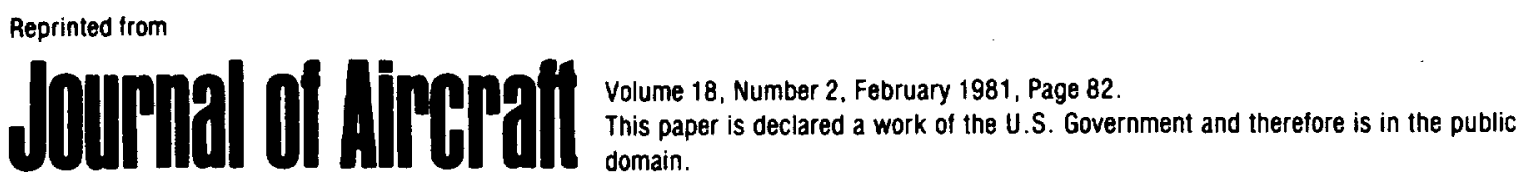




\title{
Full-Scale Wind-Tunnel Study of the Effect of Nacelle Shape on Cooling Drag
}

\author{
Victor R. Corsiglia * and Joseph Katz $\dagger$ \\ NASA Ames Research Center, Moffett Field, Calif. \\ and \\ Richard A. Kroeger $\ddagger$ \\ ARO, Inc., Tullahoma, Tenn.
}

\begin{abstract}
Tests were made in the Ames 40 by $80 \mathrm{ft}$ Wind Tunnel of a semispan wing with a nacelle (no propeller) from a typical, general aviation twinengine aircraft. Measurements were made of the effect on drag of the flow of cooling air through the nacelle. Internal and external nacelle pressures were measured. It was found that the cooling airflow accounts for about $13 \%$ of the total estimated airplane drag during both cruise and climb. The flow of cooling air through the nacelle accounts for $30 \%$ of the airflow drag component during cruise and $42 \%$ during climb; the balance, in both cruise and climb, is attributed to the external shape of the nacelle. It was suggested that improvements could possibly be made by relocating both the inlet and the outlet for the cooling air.
\end{abstract}

\section{Nomenclature}

$c \quad$ = wing chord $1.62 \mathrm{~m}(5.3 \mathrm{ft})$

$c_{d} \quad=$ section drag coefficient, $(\partial D / \partial Y) q_{\infty} c$

$C_{D} \quad=$ drag coefficient, $D / q_{\infty} S$

$C_{L} \quad=$ lift coefficient, $L / q_{\infty} S$

$C_{p} \quad=$ pressure coefficient, $P / q_{\infty}$

$D \quad=$ drag

$\mathrm{g}=$ gravitational acceleration

$k \quad=$ orifice constant

$L=$ lift

$P \quad=$ pressure

$P_{s \infty} \quad=$ freestream static pressure

$q_{\infty} \quad=$ freestream dynamic pressure, $1 / 2 \rho V_{\infty}^{2}$

$S \quad=$ reference area, exposed wing semispan, $8.6 \mathrm{~m}^{2}$ $\left(92.6 \mathrm{ft}^{2}\right)$

$\bar{S} \quad=$ surface distance $/ c$ (Fig. 12)

$V_{\infty} \quad=$ freestream velocity

$\dot{W} \quad=$ weight flow rate of air through cooling duct

$y \quad=$ spanwise ordinate

$\alpha \quad=$ angle of attack

$\beta \quad=$ percentage opening of the orifices between the upper and lower plenum

$\delta_{c f} \quad=$ cowl flap deflection

$\rho \quad=$ air density

Subscripts

$U \quad=$ upper plenum

$L \quad=$ lower plenum

\section{Introduction}

$\mathbf{R}$ ECENT interest (by NASA, universities, and industry) in the cooling of general aviation piston engines is directed at reducing drag to improve flight efficiency. The work of these institutions considers the ducting of air through the engine nacelle, and analyzes the various contributions to overall drag. This effort is an extension of work on the subject

Presented as Paper 79-1820 at the AlAA Aircraft Systems and Technology Meeting, New York, N.Y., Aug. 20-22, 1979; submitted Aug. 30, 1979; revision received April 21, 1980. This paper is declared a work of the U.S. Government and therefore is in the public domain.

*Aerospace Engineer. Member AIAA.

†NRC Associate.

$\ddagger$ Program Manager. Member AlAA. done by NACA and others between 1920 and 1950. Those studies were directed at reducing drag while providing an acceptable level of engine cooling. The work, however, was devoted to configurations that were in use during that era.

Reference 1 reports a 1929 effort by NACA to develop lowdrag cowlings for radial piston engines. That effort resulted in guidelines for the design of engine installations that were widely accepted by the industry. In those studies, a measure of cowling drag was obtained by comparing the drag of the proposed design (in a wind tunnel) with the drag of the same aircraft configuration but with a smooth nose fairing in place of the engine.

A second significant effort in the United States dealt with the development of the Ranger inverted inline aircraft engine,$^{2}$ engine installations representative of an intermediate step between the early radial engines and the present horizontally opposed designs. Reference 2 , however, focuses on the parameters associated with engine cooling and the drag aspect of the problem is ignored. Reference 3 reports on the research effort in Great Britain to study the cooling of aircraft engines used during World War II. Again, the drag aspect was considered secondarily to the cooling requirements encountered under extreme environmental conditions and at high engine-power levels.

The recent NASA effort has consisted of studies conducted by Miley and others. ${ }^{4,5}$ In those investigations, flight and ground tests were conducted in which temperature, pressure, altitude, and airspeed measurements were made to study inlet design and velocity ratio. Drag, however, was not reported because of the difficulty of making drag measurements in flight with sufficient accuracy to detect drag effects of different cooling configurations.

This paper reports on the results of an investigation at Ames Research Center that utilized the capability of the 40 by $80 \mathrm{ft}$ Wind Tunnel to measure the various increments in cooling drag accurately. A semispan wing from a typical, general aviation twin-engine aircraft was tested at full-scale flight conditions. Measurements were made of lift, drag, surface pressures, and nacelle internal pressures. The study was directed at finding the effects of external nacelle shape and of the inlet and exit design of the cooling channel. The engine and its baffle design were simulated in the experiment, but their characteristics were not considered in detail. Research on engine and baffle design is being conducted at Lewis Research Center. ${ }^{6}$ 


\section{Experimental Procedure}

\section{Definition of Cooling Drag}

In the present tests, cooling drag was defined in a manner based upon the reference configuration technique used by Weick' (Fig. 1). In order to establish a reference configuration, a low-drag fairing was used to seal the inlets and exit of the cowls. The reference cowling is, in concept, the one that would be used if there were no cooling requirement. As noted in Fig. 1, cooling drag is defined as the difference between the drag of the test and reference configurations.

\section{Apparatus}

A sketch of the test and reference configurations is presented in Fig. 2. The constant chord wing had a $5.33 \mathrm{~m}$ $(17.5 \mathrm{ft})$ semispan, and the nacelle centerline was located at $24 \%$ semispan from the wing root. Photographs of the test and reference configurations, as they were installed in the Ames 40 by $80 \mathrm{ft}$ Wind Tunnel, are shown in Fig. 3. Angle of attack was varied by moving the model relative to the largeend plane, which was fixed to the wind-tunnel floor. The wind-tunnel scales therefore responded only to air loads on the wing and nacelle.

The internal geometry of the nacelle (Fig. 4) consisted of an inlet, upper plenum, lower plenum, and cowl flap exit. The resistance encountered by the flow of cooling air around a piston engine was simulated in these tests by orifices in the plenum divider plate that separated the upper and lower plenum chambers. The size of the orifices was adjustable so that engines with different air resistances could be simulated. The orifices were calibrated for flow rate as a function of pressure drop by removing the cowl flap and installing an external Venturi meter (Figs. 4 and 5).

TEST CONFIGURATION

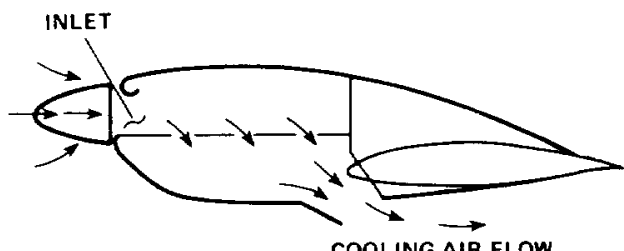

COOLING AIR FLOW

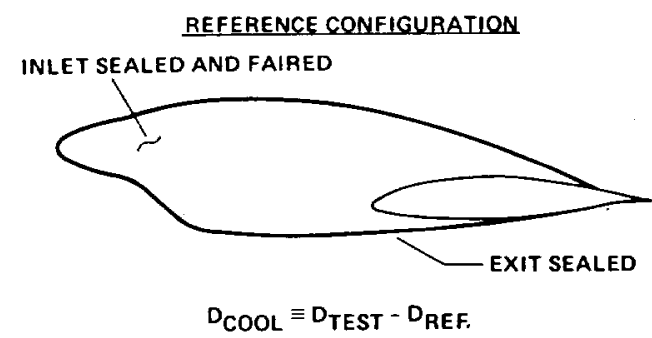

Fig. 1 Test and reference configurations.

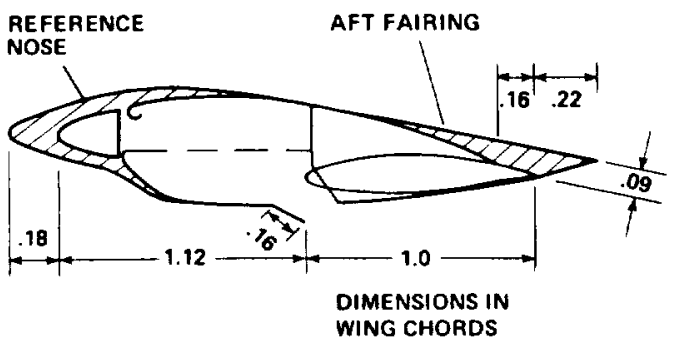

Fig. 2 Model dimensions with and without reference nose and aft fairing (dimensions in wing chords).
A total head rake was used in the wake of the nacelle and the wing during some of the tests in order to obtain the spanwise distribution of section drag coefficient (Figs. 3a and 5). The rake, which included both static and total pressure orifices, extended about 0.2 chord above the wing and 0.3 chord below the wing to insure that the entire viscous wake was captured.

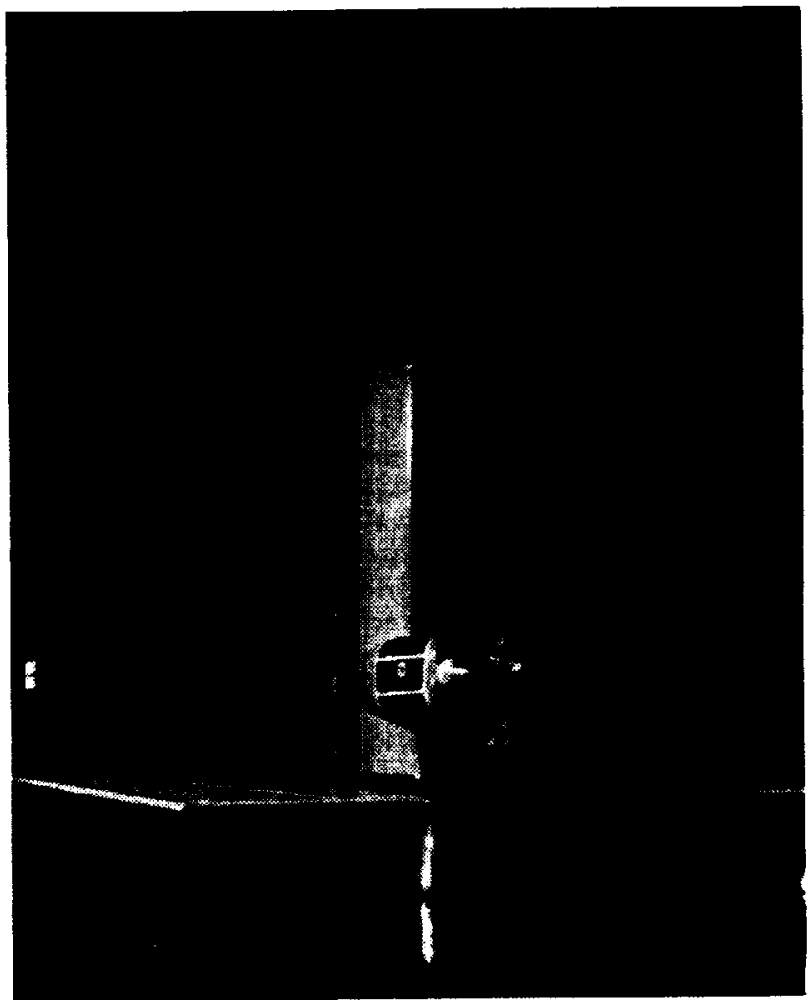

a)

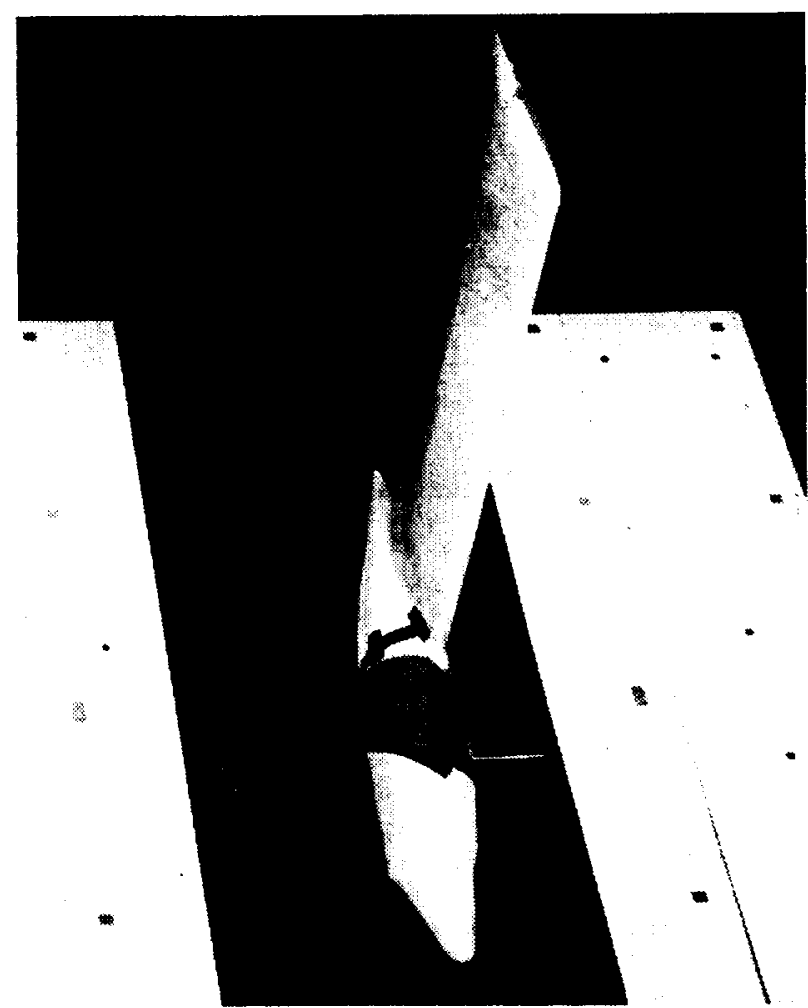

b)

Fig. 3 Wing installed in Ames 40 by 80 ft Wind Tunnel: a) test configuration, b) reference configuration. 


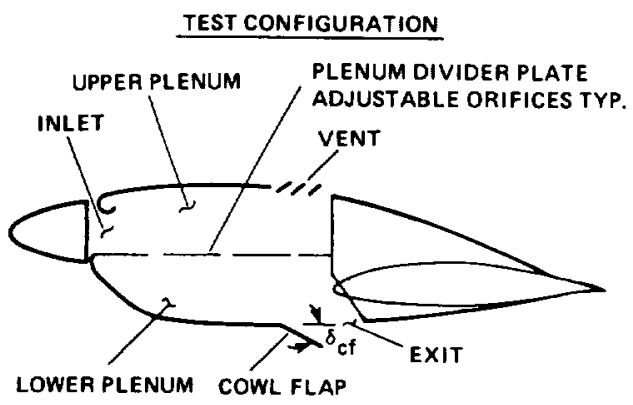

CALIBAATION CONFIGURATION

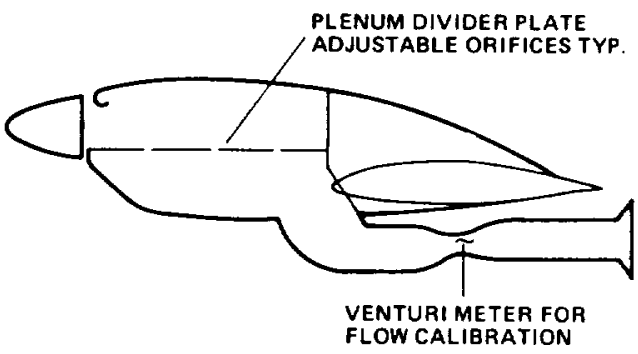

Fig. 4 Nacelle arrangement illustrating venturi meter for orifice calibration.

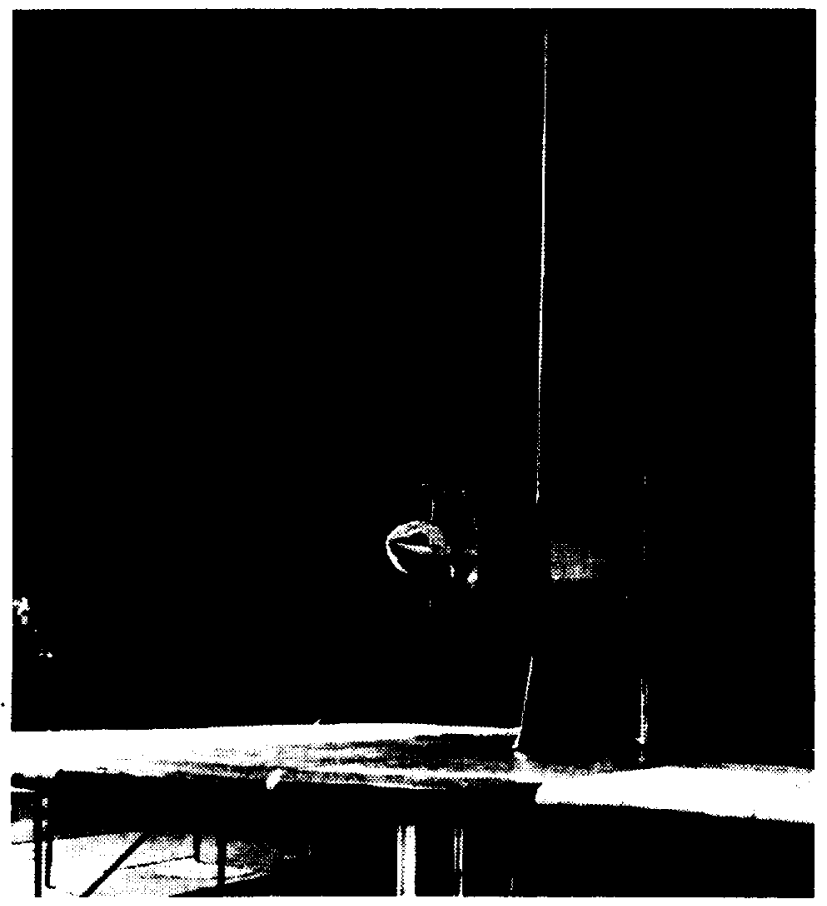

Fig. 5 Venluri meter and aft momentum rake.

Pressure measuring instruments were located on the external surface of the nacelle and in the upper and lower plenum. The upper plenum instrumentation (Fig. 6) consisted of Kiel probes in 8 of the 10 orifice openings. Also, six static pressure taps were installed in the plenum divider plate to measure the upper plenum pressure (taps 9-14 on Fig. 6). In the lower plenum, the total pressure was measured with a piccolo tube (Fig. 6) and four Kiel probes just forward of the cowl flap exit. The piccolo tube, identical in design to that used by Miley, ${ }^{4}$ consisted of a U-shaped porous tube.

\section{Orifice Calibration}

The flow rate through the orifices in the plenum divider plate was calibrated by installing the venturi tube at the exit of
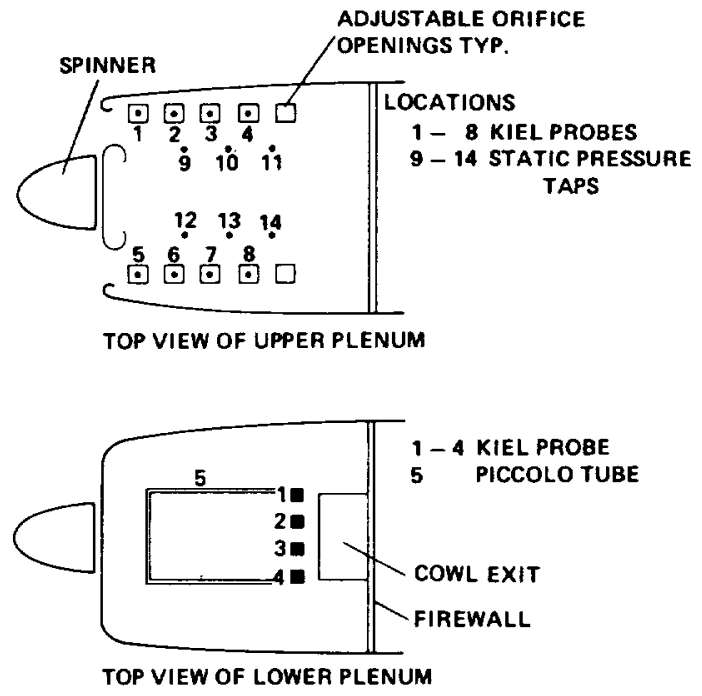

Fig. 6 Nacelle internal pressure instrumentation.

the cooling duct and then operating the wind tunnel at various speeds for various openings of the orifices. The flow rate through the venturi was then obtained as a function of the pressure difference between the upper and lower plenum. In order to establish a value representative of the upper plenum pressure, several orientations of the Kiel probes were tested to determine the largest reading (i.e., the correct total pressure) at each of the eight Kiel probe locations in the upper plenum. Kiel probe results were generally in agreement with the static tap results. The Kiel probes in the lower plenum yielded slightly higher values than the piccolo tube. In both the upper and lower plenums, only the largest recorded pressures were used in the analysis. The flow rate and pressure data were then correlated by use of the following expression:

$$
\dot{W}=k\left[(2 / \rho)\left(P_{U}-P_{L}\right)\right]^{1 / 2}
$$

where $k$ is a constant that was different for each orifice opening (see Table 1). A straight line closely approximated the data for all of the orifice openings.

\section{Accuracy of Drag Measurement}

The least count of the drag scale was checked by adding known weights to this scale under the dynamic conditions that exist when the tunnel is operating with the model installed and then by recording and processing those data. The errors in the measurement of the known added weight varied from zero to a maximum of $1.1 \mathrm{~kg}(2.5 \mathrm{lb})$, with an average error of $0.7 \mathrm{~kg}$ $(1.5 \mathrm{lb})$. This average corresponds to $4 \%$ of the measured cooling drag in the cruise configuration (shown later).

\section{Results and Discussion}

\section{Effect of Aft Fairing}

Test runs were made with the venturi removed and the cowl flap installed for two flight conditions: 1) cruise ( $V_{\infty}=156$ knots, $\alpha=2.3 \mathrm{deg}$ ), and 2) climb ( $V_{\infty}=94$ knots, $\alpha=8 \mathrm{deg}$ ). With the angle of attack, tunnel speed, and cowl flap setting

Table 1 Values for orifice flow constant $k$ for each orifice opening, $\beta$

\begin{tabular}{rcc}
\hline \hline$\beta, \%$ & $\mathrm{~kg} / \mathrm{m}$ & $\mathrm{k},(\mathrm{lb} / \mathrm{ft})$ \\
\hline 20 & 0.021 & $(0.014)$ \\
40 & 0.033 & $(0.022)$ \\
60 & 0.045 & $(0.030)$ \\
80 & 0.052 & $(0.035)$ \\
100 & 0.066 & $(0.044)$ \\
\hline
\end{tabular}




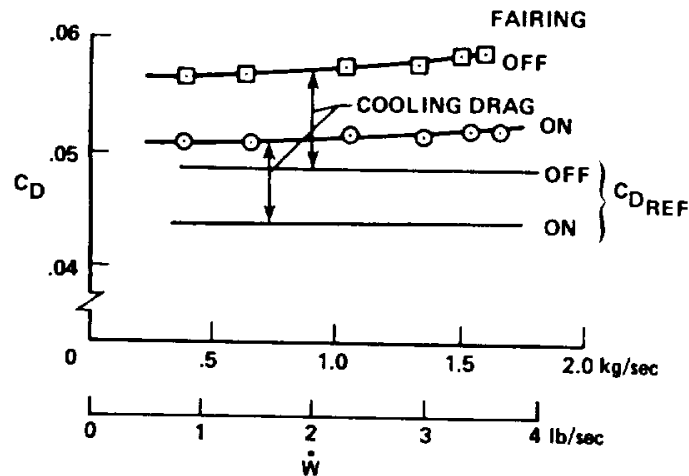

Fig. 7 Effect of aft fairing on drag (scale data) for both test and reference configurations: climb: $\alpha=8 \mathrm{deg}, V_{\infty}=94 \mathrm{knots}, \delta_{c f}=30$ deg.
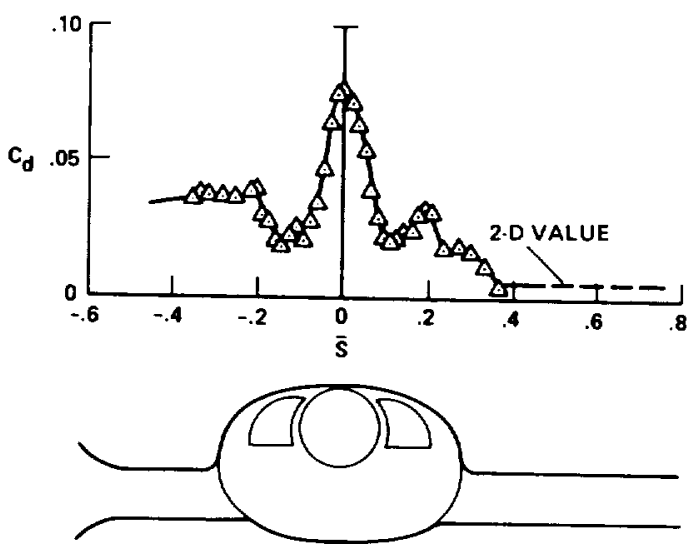

a)

b)

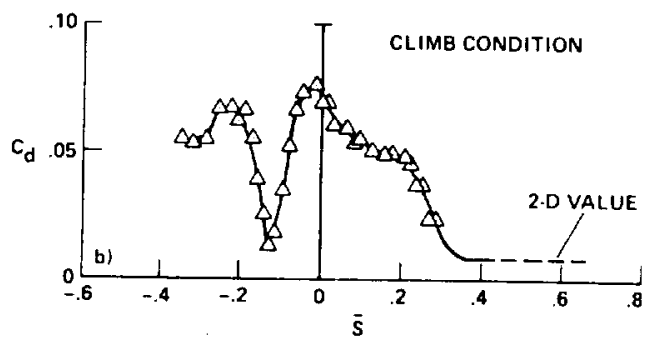

Fig. 8 Section drag coefficient as function of span as determined by integration of siatic and total pressures on wake momentum rake, afi fairing off: a) cruise, $\alpha=2.3 \mathrm{deg}, V_{\infty}=156 \mathrm{knots}, \delta_{c f}=0$ deg; b) climb, $\alpha=8 \mathrm{deg}, V_{\infty}=94 \mathrm{knots}, \delta_{c f}=30 \mathrm{deg}$.

fixed, data were recorded for a range of orifice openings. Figure 7 shows the variation of the drag coefficient with the nacelle flow rate, both with and without the aft fairing installed. The $C_{D}$ levels of the reference configuration are also shown. The effect of the fairing on the drag of the nacelle is clear. This can also be seen in the distribution of section drag coefficient (Fig. 8). (The momentum rake data shown have been integrated using the method of Betz found in Schlichting ${ }^{7}$ to obtain the section drag coefficient.) As shown, the nacelle region of the span is a major contributor to the wing drag, especially in the climb configuration. Cooling drag is also dependent on the external nacelle shape. Cooling drag is less with the aft fairing installed $\left(C_{D}=0.0098\right.$ vs 0.0085 , Fig. 6) than without the aft fairing. This is interpreted to be a result of an interaction between the boundary layer near the inlet upper surface and the aft upper surface of the nacelle. Tuft studies of the flow in this inlet region showed that the flow is generally attached. Pressure contours (Fig. 9) show a

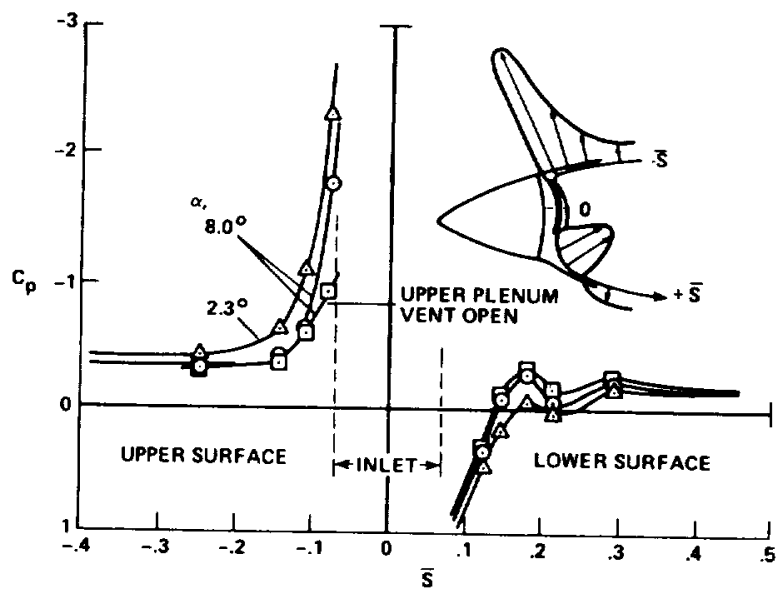

Fig. 9 Streamwise contours of surface pressure along curve passing vertically through cooling inlet: $\dot{W}=1.2 \mathrm{~kg} / \mathrm{s}(2.7 \mathrm{lb} / \mathrm{s}), V_{\infty}=156$ knots $(\alpha=2.3 \mathrm{deg}), V_{\infty}=94$ knots $(\alpha=8 \mathrm{deg})$, aft fairing off.

sharp suction peak near the inlet upper surface, however, implying high velocities and a thickened boundary layer that is convected back over the upper surface of the nacelle. The adverse effect of this thickened boundary layer is apparently lessened by the presence of the aft fairing. Tuft studies in the aft upper surface region showed that the effect of the aft fairing was to suppress the separated flow that existed with the fairing removed.

\section{Inlet Design}

Another feature worth noting on Fig. 9 is the lack of symmetry in the profiles between the upper and lower surface. The inlet would be more effective if it were aligned with the local streamlines and centered with respect to the oncoming flow. To achieve this, however, the inlet would have to be moved to the lower front of the nacelle, which is below the propeller hub. The present location is dictated by the need to supply air to a plenum above the engine. An upflow cooling system would move the high-pressure plenum below the engine and allow an inlet location more compatible with the external flow.

\section{Cooling Drag}

Figure 10 shows cooling drag results for three cowl flap settings and for both the climb and cruise conditions. Typical cowl flap setting and flow rates used in climb for the nacelle being tested are $\delta_{c f}=30 \mathrm{deg}$ and $\dot{W}=1.4 \mathrm{~kg} / \mathrm{s}(3 \mathrm{lb} / \mathrm{s})$. These values can be seen to correspond to an orifice opening of $\beta=60 \%$, which is therefore the porosity which simulates the engine usually installed in the nacelle. The dashed curve on the figure is $\beta=60 \%$ constant. As can be seen, an increase in the cowl flap deflection from $\delta_{c f}=0$ to $30 \mathrm{deg}$ increased the flow rate from $\dot{W}=0.7$ to $1.4 \mathrm{~kg} / \mathrm{s}(1.5$ to $3.0 \mathrm{lb} / \mathrm{s})$ which caused an increase in the cooling drag from $C_{D}=0.0050$ to 0.0085 . Obviously, the cowl flap is a major contributor to cooling drag. In cruise, the cooling drag is $C_{D}=0.0051$ $(\beta=60 \%)$. The drag coefficient for the airplane with this wing can be estimated using published data on horsepower required, speeds, and altitudes. Using those values, the cooling drag in cruise due to two nacelles is $13 \%$ of the estimated total airplane drag. Similarly, in the climb condition the cooling drag is $7 \%$ of the airplane drag for $\delta_{c f}=0$ deg and $12 \%$ for $\delta_{c f}=30 \mathrm{deg}$.

\section{Upper Plenum Vent}

The model photo (Fig. 3a) and sketch (Fig. 4) indicate a vent on the nacelle upper surface at the aft end of the upper plenum. This vent, which prevents excessive upper plenum temperatures when the aircraft is being operated on the 
ground, was sealed throughout the tests. The effect on drag caused by opening the vent was small $\left(C_{D}=0.0005\right.$ in Fig. 11) in spite of the fact that pressure measurements on the external surface near the vent (Fig. 12b) and within the upper plenum (Fig. 13) indicate a pressure difference of about $C_{p}=1.0$, which corresponds to a substantial outflow from the vent. The peak suction on the inlet upper surface was reduced to about half (Fig. 9) as a result of opening the vent. Apparently, improved flow at the inlet lip due to increasing the flow through the inlet compensates for whatever interference drag results from the outflow through the vent.

\section{Exi1 Location}

The cowl flap is on the nacelle lower surface where a high static pressure is induced by the wing (Fig. 4). Nacelle external surface pressure measurements were made to study possible alternative exit locations that would permit the low pressure induced by the wing to be used to reduce or eliminate the requirement for a cowl flap. Figure 12a shows the locations of the pressure measurements and Figs. $12 \mathrm{~b}-12 \mathrm{~d}$ present the results. The static pressure at the existing exit location must be interpolated between stations $A$ and $C$. As can be seen, the existing cowl flap is located about where the static pressure is at a maximum (i.e., a maximum in back pressure to the flow of cooling air). Lowest pressures are found near the upper surface of the wing leading edge. At station B near $\bar{S}=0.3$ the reduction in static pressure from the existing cowl flap
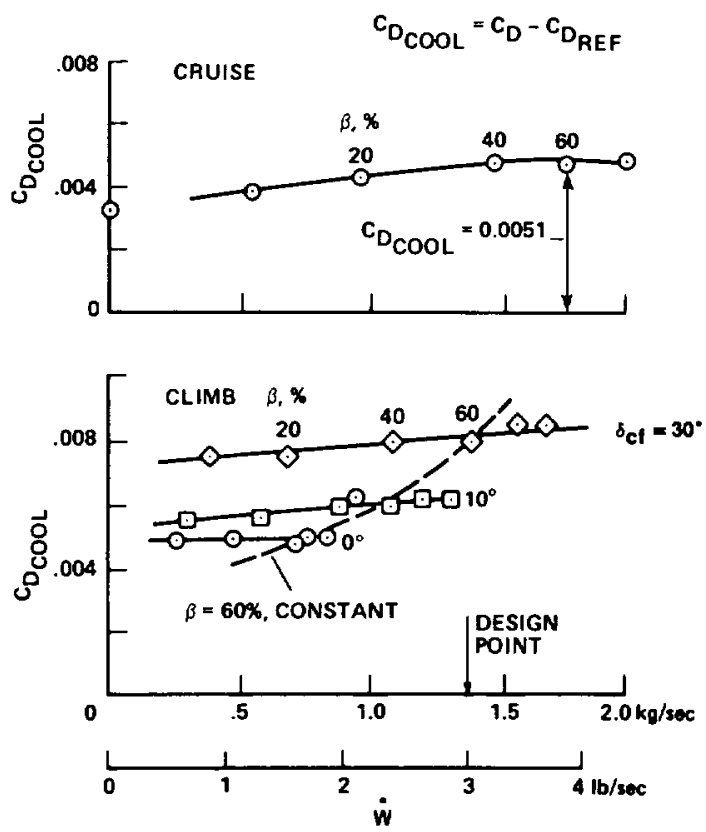

Fig. 10 Cooling drag (scale data) $\left(C_{D C O p l}=C_{D}-C_{D p F F}\right.$ ) as function of cooling now rate for both cruise and climb conditions, aft fairing on: cruise, $\alpha=2.3 \mathrm{deg}, V_{\infty}=156 \mathrm{knols}$; climb, $\alpha=8 \mathrm{deg}$, $V_{\infty}=94$ knots.

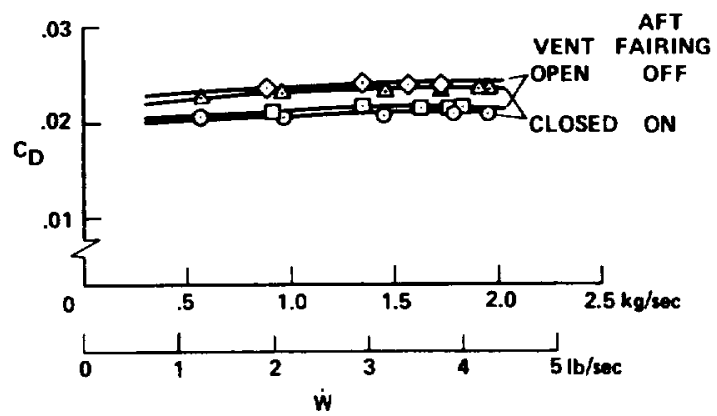

Fig. 11 Effecl on drag caused by opening and closing upper plenum vent (scale data): $\alpha=2.3 \mathrm{deg}, V_{\infty}=156$ knots.

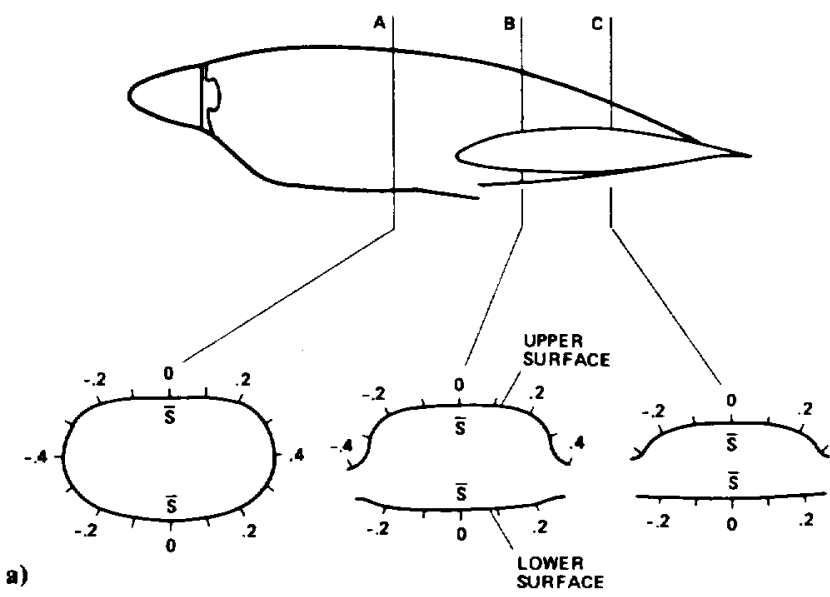

a)

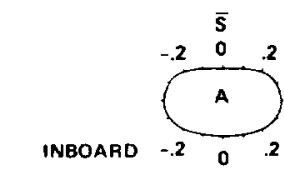

OUTBOARD

b)

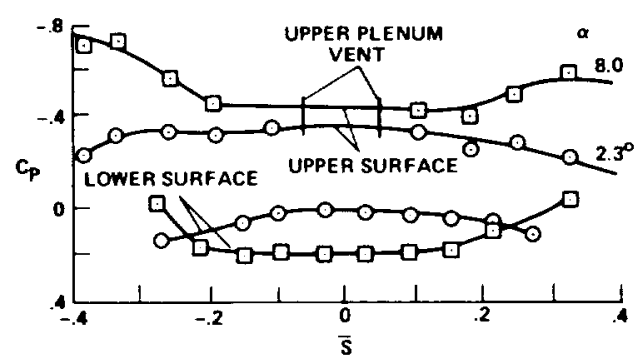

c)
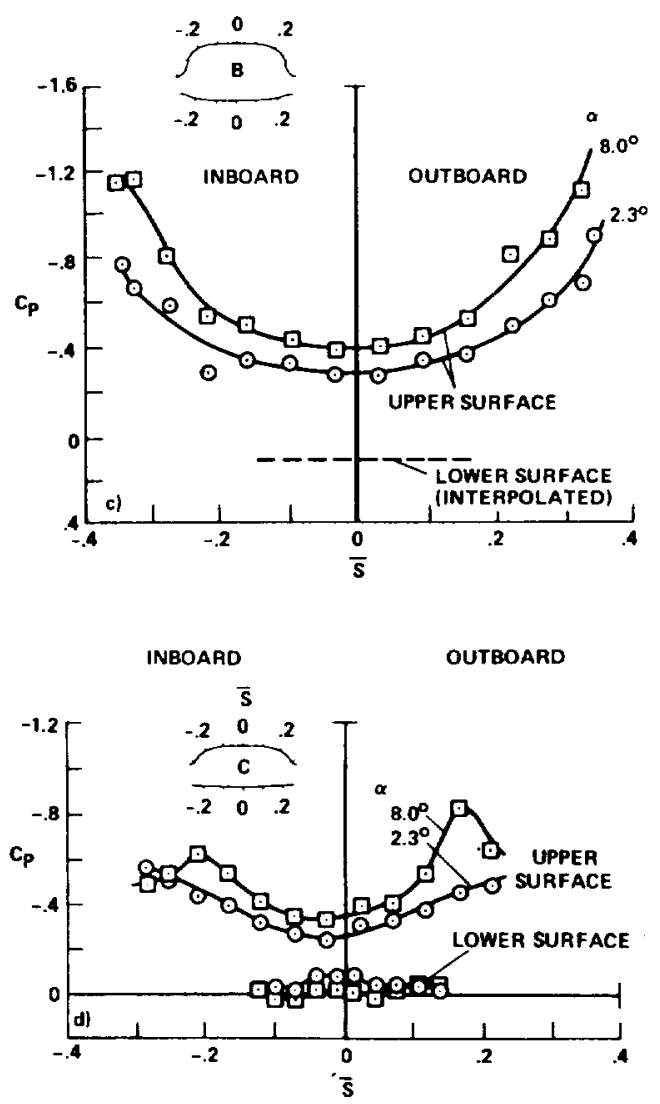

Fig. 12 Spanwise contours of surface pressure at three chordwise stations above and below nacelle including existing and possible alternative cowl exit locations, aft fairing off, $\alpha=8 \mathrm{deg}, V_{\infty}=94$ knots, $\delta_{c f}=10$ deg: a) contour locations; b) surface pressure at station $A$; c) surface pressure at station $B$; d) surface pressure at station $\mathbf{C}$. 
location is about $C_{p}=1.0(\alpha=8 \mathrm{deg})$. The change in the pressure coefficient in the lower plenum that is associated with a cowl flap change from $\delta_{c f}=0$ to $30 \mathrm{deg}$ (not shown) is $C_{p}=0.36$. It appears, therefore, that regions of sufficiently low pressure induced by the wing are available so that adequate nacelle cooling flow could be induced without the use of a cowl flap. Further research is required to determine possible adverse effects on wing $L / D$ and $C_{L_{\max }}$ that might result from the use of such an exit location.

\section{Internal Cooling Drag}

An internal cooling drag can be inferred from the measurements of flow rate and total pressure in the upper and lower plenums. The expressions for this cooling drag are obtained from total pressures as follows:

Inlet:

$$
D=\frac{\dot{W}}{g}\left[V_{\infty}-\sqrt{\frac{2}{\rho}}\left(P_{U}-P_{S_{\infty}}\right)\right]
$$

Total

Internal:

$$
D=\frac{\dot{W}}{g}\left[V_{\infty}-\sqrt{\frac{2}{\rho}}\left(P_{U}-P_{S_{\infty}}\right)\right]
$$

Engine: $\quad D=D_{\text {total internal }}-D_{\text {inlet }}$

Figure 13 presents the upper plenum pressures as functions of weight rate of flow of cooling air for the climb and cruise configurations. For these data, an insert was installed in the upper plenum; the insert approximated the dimension of the engine that normally occupies the upper plenum volume. The upper plenum pressure is noted to be about $63 \%$ of $q_{\infty}$ for both the climb and cruise conditions $(\beta=60 \%)$. Table 2 presents a comparison of the present results and flight-test data for the upper plenum pressure and the pressure difference across the engine. Although the flight-test aircraft is not identical to the wind-tunnel model, the geometry and the flow rates are similar. The results are similar for the two sets of data except for the engine pressure difference in the cruise condition.

The internal drag coefficient values are shown in Fig. 14 for the cruise and climb condition. For $\beta=60 \%$ the inlet contributes $44 \%$ of the total internal drag for the cruise condition and $23 \%$ for the climb condition. For both the cruise and the climb condition $(\beta=60 \%)$ the internal drag is less than the ram drag, indicating that some momentum is recovered at the exit. At lower now rates in the climb condition, the measured internal drag exceeds the ram drag; however, the pumping action of the cowl flap generates the necessary flow rate of cooling air.

Figure 15 summarizes the breakdown of all the components of drag thus far presented. As can be seen, the internal cooling drag accounts for $30 \%$ of the measured cooling drag for cruise and $42 \%$ for climb. The remaining drag component is associated with the external shape. That is, the external

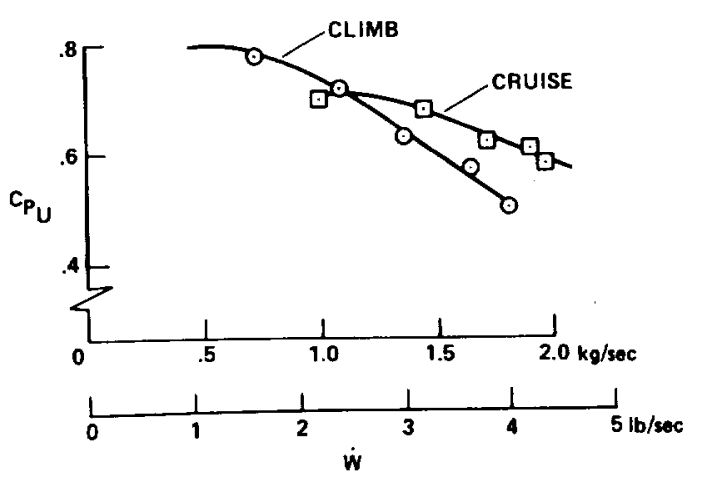

Fig. 13 Upper plenum total pressure, aft fairing on: climb, $\alpha=8 \mathrm{deg}$, $V_{\infty}=94 \mathrm{knots}, \delta_{c f}=30 \mathrm{deg}$; cruise, $\alpha=2.3 \mathrm{deg}, V_{\infty}=156 \mathrm{knots}$, $\delta_{\mathrm{c} f}^{\infty}=\mathbf{0} \mathrm{deg}$.

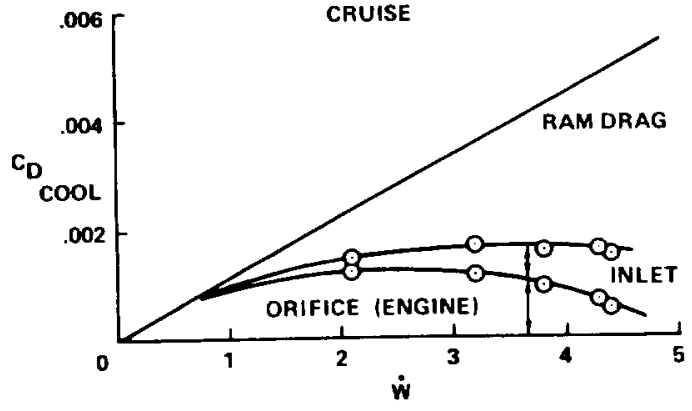

a)

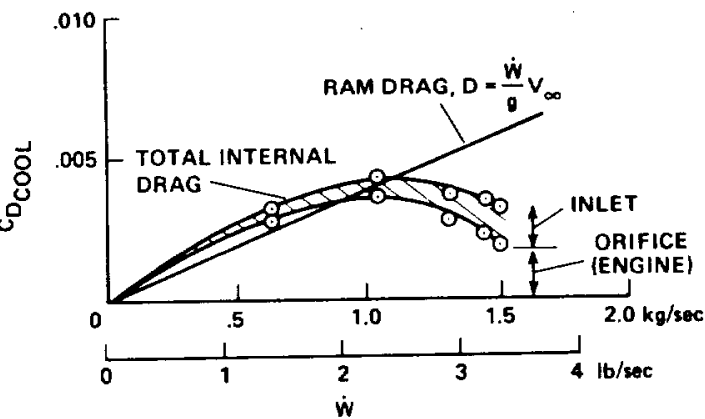

b)

Fig. 14 Internal nacelle cooling drag as determined by total pressure and flow rate in upper and lower plenum, aft fairing on: $a)$ cruise, $\alpha=2.3 \mathrm{deg}, V_{\infty}=156 \mathrm{knots}, \delta_{c f}=0$ deg; b) climb, $\alpha=8 \mathrm{deg}, V_{\infty}=94$ knots, $\delta_{c f}=30$ deg.

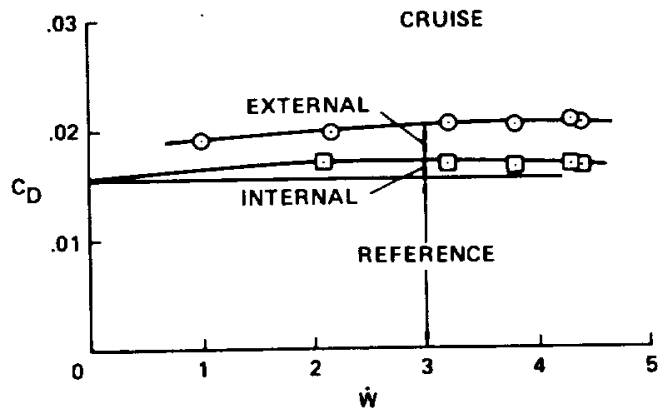

a)

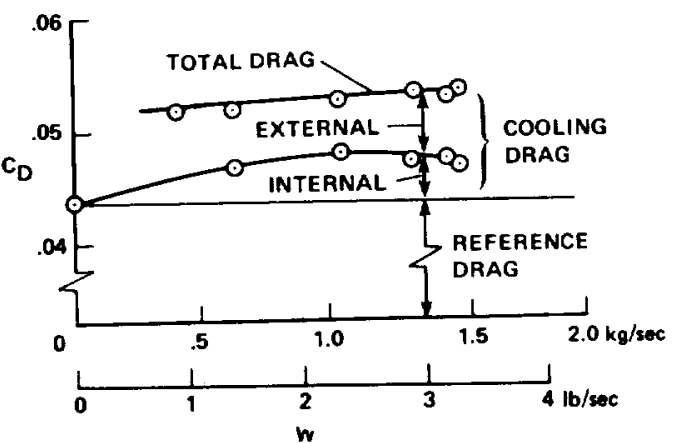

Fig. 15 Summary of drag coefficient breakdown, aft fairing on: a) cruise, $\alpha=2.3 \mathrm{deg}, V_{\infty}=156$ knots, $\left.\delta_{c f}=0 \mathrm{deg} ; \mathrm{b}\right) \mathrm{climb}, \alpha=8$ deg, $V_{\infty}=156$ knots, $\delta_{c f}=30 \mathrm{deg}$.

Table 2 Comparison of total pressure coefficient measured in wind Iunnel with flight-test data

\begin{tabular}{lcccr}
\hline & \multicolumn{2}{c}{ Climb } & \multicolumn{2}{c}{ Cruise } \\
& $\begin{array}{l}\text { Wind } \\
\text { tunnel }\end{array}$ & Flight $^{\mathrm{a}}$ & $\begin{array}{l}\text { Wind } \\
\text { tunnel }\end{array}$ & Flight \\
\hline $\begin{array}{l}\text { Upper plenum } \\
\begin{array}{l}\text { Engine pressure } \\
\text { difference }\end{array}\end{array}$ & 0.64 & 0.64 & 0.63 & 0.69 \\
\hline \hline
\end{tabular}

${ }^{a}$ From Ref. 4. 
contour has been configured to provide an inlet and an exit. As a result, the external drag is higher than if the inlet and exit were not required.

\section{Conclusion}

Measurements were made of the drag and pressure distribution on a wing and nacelle from a typical, general aviation twin-engine aircraft in order to assess the drag penalties associated with ducting cooling air through the engine nacelle. It was found that the cooling drag was about $13 \%$ of the total airplane drag. About $30 \%$ of the cooling air drag component of the total aircraft drag was internal during cruise, and about $42 \%$ during climb; the balance is associated with the external shape of the nacelle. In climb, cooling drag could be reduced to about $7 \%$ of total airplane drag if a cowl flap was not required. The primary function of the cowl flap is to reduce the pressure in the lower plenum and thereby increase the flow rate to the level required for engine cooling. It was found that the possibility exists for decreasing this lower plenum pressure by relocating the exit. In fact, surface pressure measurements on the nacelle exterior indicate that the pressure in the lower plenum can be reduced more by using the pressure field of the wing than by deflecting the cowl flap to $30 \mathrm{deg}$.

The existing location of the inlets was also found to be a source of drag. The small radii on the upper inlet lip resulted in increased drag on the aft upper surface of the nacelle. Also, the inlet pressure recovery was low $\left(63 \%\right.$ of $\left.q_{\infty}\right)$. It appears that the external drag could be reduced by relocating the inlet to the lower front of the nacelle where it would be better aligned with the oncoming flow. Such a location should also improve inlet pressure recovery.

\section{References}

'Weick, F. E., "Drag and Cooling with Various Forms of Cowling for a 'Whirlwind' Radial Aircooled Engine I and II," NACA TR-313 and NACA TR-314, 1929.

${ }^{2}$ Hammen, T.F., Jr., and Rowley, W.H., "Factors Pertaining to Installation of Inverted In-Line Air-Cooled Aircraft Engines," $S A E$ Journal, Vol. 54, March 1946, pp. 130-152.

${ }^{3}$ Hartshorn, A.S. and Nicholson, L.F., "The Aerodynamics of the Cooling of Aircraft Reciprocating Engines," ARC R\&M 2498, 1956.

${ }^{4}$ Miley, S.J., "An Investigation of the Aerodynamics and Cooling of a Horizontally Opposed Engine Installation," Paper 770467 presented at SAE Business Aircraft Meeting, Wichita, Kan., March 29-April 1, 1977.

${ }^{5}$ Miley, S.J., Cross, E.J., Jr., Lawrence, D.L., and Owens, J.K., "Aerodynamics of Horizontally Opposed Aircraft Engine Installations," Paper 77-1249 presented at AlAA Aircraft Systems and Technology Meeting, Seattle, Wash., Aug. 22-24, 1977.

${ }^{6}$ Kempke, E. and Willis, E.A., "An Overview of NASA Research on Positive Displacement Type General Aviation Engines," Paper 79 1824 presented at AIAA Aircraft Systems and Technology Meeting, New York, Aug. 20-22, 1979.

${ }^{7}$ Schlichting, H., Boundary Layer Theory, 4th ed., McGraw-Hill Book Co., New York, 1960, pp. 616-618. 